\title{
Dietary pomegranate by-product improves oxidative stability of lamb meat
}

\section{Article}

\section{Accepted Version}

Creative Commons: Attribution-Noncommercial-No Derivative Works 4.0

Natalello, A., Priolo, A., Valenti, B., Codini, M., Mattioli, S., Pauselli, M., Puccio, M., Lanza, M., Stergiadis, S. and Luciano, G. (2020) Dietary pomegranate by-product improves oxidative stability of lamb meat. Meat Science, 162. 108037. ISSN 0309-1740 doi:

https://doi.org/10.1016/j.meatsci.2019.108037 Available at https://centaur.reading.ac.uk/88016/

It is advisable to refer to the publisher's version if you intend to cite from the work. See Guidance on citing.

To link to this article DOI: http://dx.doi.org/10.1016/j.meatsci.2019.108037

Publisher: Elsevier

All outputs in CentAUR are protected by Intellectual Property Rights law, including copyright law. Copyright and IPR is retained by the creators or other copyright holders. Terms and conditions for use of this material are defined in the End User Agreement.

\section{www.reading.ac.uk/centaur}

\section{CentAUR}


Central Archive at the University of Reading

Reading's research outputs online 


\section{Dietary pomegranate by-product improves oxidative stability of lamb meat}

2

3 Antonio Natalello ${ }^{\mathrm{a}, *}$, Alessandro Priolo ${ }^{\mathrm{a}}$, Bernardo Valenti ${ }^{\mathrm{b}}$, Michela Codinic ${ }^{\mathrm{c}}$, Simona

4 Mattioli $^{\mathrm{b}}$, Mariano Pauselli ${ }^{\mathrm{b}}$, Mario Puccio ${ }^{\mathrm{a}}$, Massimiliano Lanza ${ }^{\mathrm{a}}$, Sokratis Stergiadis ${ }^{\mathrm{d}}$,

$5 \quad$ Giuseppe Luciano ${ }^{\mathrm{a}}$

6

7 a University of Catania, Dipartimento di Agricoltura, Alimentazione e Ambiente (Di3A), Via

8 Valdisavoia 5, 95123, Catania, Italy

9 b University of Perugia, Dipartimento di Scienze Agrarie, Alimentari e Ambientali (DSA3), Borgo XX

10 Giugno 74, 06123, Perugia, Italy

11 c University of Perugia, Dipartimento di Scienze Farmaceutiche, Via Ariodante Fabretti 48, 06123,

12 Perugia, Italy.

13 d University of Reading, Department of Animal Sciences, School of Agriculture, Policy and

14 Development, PO Box 237, Earley Gate, Reading RG6 6AR, United Kingdom

15

16 *Corresponding author. E-mail address: antonio.natalello@unict.it

17 


\section{Highlights}

- The inclusion of $20 \%$ whole pomegranate by-product (WPB) in lamb diet was evaluated

- WPB is rich in bioactive compounds (e.g. conjugated FA, vitamin E and phenols)

- WPB-lamb meat contained higher concentration of vitamin E and PUFA

- Lipid oxidation and metmyoglobin formation of meat were reduced by WPB treatment

- Dietary WPB increased the meat antioxidant capacity in the lipophilic fraction 
18 ABSTRACT:

19 This study investigated the effect of including whole pomegranate by-product in lamb diet on 20 meat oxidative stability. Seventeen lambs were assigned to two experimental treatments and 21 fed a cereal-based concentrate $(\mathrm{CON})$ or the same concentrate where $200 \mathrm{~g} / \mathrm{kg} \mathrm{DM}$ of cereals 22 were replaced by whole pomegranate by-product (WPB). Meat from WPB-fed lambs had a 23 greater concentration of vitamin $\mathrm{E}$ ( $\alpha$ - and $\gamma$-tocopherols), polyunsaturated fatty acids (PUFA), 24 highly peroxidizable PUFA and a higher peroxidability index $(P<0.05)$. Feeding WPB limited 25 the formation of metmyoglobin $(P=0.05)$ and reduced lipid oxidation (TBARS values) after 267 days of storage for raw meat $(P=0.024)$ or 4 days for cooked meat $(P=0.006)$. Feeding 27 WPB increased meat antioxidant capacity (ORAC assay) in the lipophilic fraction $(P=0.017)$, 28 but not in the hydrophilic. These results suggest that vitamin $\mathrm{E}$ in the pomegranate by-product 29 contributed to the higher antioxidant capacity of meat from the WPB-fed lambs.

30

31 KEYWORDS: pomegranate by-product; lipid oxidation; meat quality; vitamin E; 32 antioxidants; phenolic compounds. 


\section{Introduction}

36

The agro-industrial by-products have long been used in ruminant feeding as an effective strategy to reduce the cost of the diet. Furthermore, the use of alternative feeds that do not compete with human foods is currently one of the primary objectives for the scientific community and the re-use of agro-industrial wastes is pivotal to mitigate their impact on the environment (Salami et al., 2019). Among the many agro-industrial wastes available, pomegranate (Punica granatum L.) by-products are gaining enormous interest due to the global increase in consumption of pomegranate juice or ready-to-eat arils, also linked to the recognition of its potential health properties. Pomegranate fruit contains numerous bioactive compounds, such as peculiar conjugated fatty acids, phenolic compounds and vitamins, which possess antioxidant, antimicrobial, anti-inflammatory, antitumoral and immunomodulatory properties (Viuda-Martos, Fernández-López, \& Pérez-Álvarez, 2010; Johanningsmeier \& Harris, 2011).

The pomegranate by-products have a high nutritional value as ruminant feeds, and can be effectively used in ruminant diets to replace cereals. In a previous study, dietary administration of fresh pomegranate peels to beef calves increased feed intake and the concentration of $\alpha$ tocopherol in plasma (Shabtay et al., 2008). Subsequent studies reported evidences of the beneficial effects of dietary pomegranate seed pulp on goat kids' antioxidant status (Emami, Ganjkhanlou, Fathi Nasri, Zali, \& Rashidi, 2015) and meat fatty acid composition (Emami, Fathi Nasri, Ganjkhanlou, Rashidi, \& Zali, 2015). Recently, we also observed a desirable increment of the polyunsaturated fatty acids (PUFA) in meat (Natalello et al., 2019) and milk (Valenti, Luciano, et al., 2019) when sheep diets were supplemented with a dried whole pomegranate by-product (WPB), which contained both seeds and peels. Nevertheless, although a high concentration of PUFA in meat is considered desirable from a human health perspective, the higher susceptibility of PUFA to peroxidation may drastically reduce meat shelf-life 
60 (Bekhit, Hopkins, Fahri, \& Ponnampalam, 2013). Few studies have investigated the shelf-life

61 of meat from ruminants fed with pomegranate by-products. Emami, Fathi Nasri, Ganjkhanlou, with $150 \mathrm{~g} / \mathrm{kg}$ (dry matter basis) of pomegranate seed pulp. These authors mainly attributed the reduction in lipid oxidation and colour discoloration to the phenolic compounds present in the by-product. Nevertheless, the concentration of total phenols in pomegranate seed is not high, especially if compared to other portions of the fruit, such as peels (Pande \& Akoh, 2009; Orak, Yagar,\& Isbilir, 2012; Natalello et al., 2020). Moreover, as stated above, pomegranate fruits and the by-products residual after juice extraction contain other bioactive compounds, such as vitamin E, which could play a major role in determining the stability of meat to oxidative deterioration (Bellés, Campo, Roncalés, \& Beltrán, 2019).

To our knowledge, no other studies have tested the dietary inclusion of whole pomegranate byproduct on meat oxidative stability. Therefore, the aim of the present study was to investigate the effect of feeding lambs with WPB on the resistance of meat to oxidation. We hypothesized that the diverse bioactive molecules present in the WPB could delay the oxidative deterioration even in meat with a high PUFA content. To test this hypothesis, we used the same animals from the experiment by Natalello et al. (2019) and we evaluated the vitamin E and the antioxidant capacity in lipophilic and hydrophilic fraction in the muscle, as well as the colour and lipid stability in meat preserved in common retail conditions.

\section{Materials and methods}

\subsection{Whole pomegranate by-product}

The experimental feeding trial is described in detail by Natalello et al. (2019). Briefly, fresh pomegranate fruits, from Wonderful variety, were processed in a local juice manufacturing company (Catania, Sicily, Italy) by mechanically halving and squeezing the fruit. After 
processing, the residual part containing peels, seeds, membranes and portion of arils was

86 collected and dried in a ventilated oven set at $40{ }^{\circ} \mathrm{C}$ for approximately 36 hours until constant weight. Chemical composition and antioxidant capacity of the dried residual part are presented in Table 1.

\subsection{Animals and experimental treatments}

The experimental procedures were approved by the University of Catania (approval: 015CT325). The animals were raised at the university's experimental farm (Catania, Italy; $37^{\circ} 24^{\prime} 35.3^{\prime \prime} \mathrm{N} 15^{\circ} 03^{\prime} 34.9^{\prime}$ 'E) and handled by specialized personnel following the European Union Guidelines (2010/63/ EU Directive). As described by Natalello et al. (2019), the trial involved seventeen Comisana male lambs, born within an interval of 10 days in the same commercial farm. At 60 days of age, animals were transported to the university facilities, weighed (average body weight $14.82 \mathrm{~kg} \pm 2 \mathrm{~kg}$ ) and allocated indoors in individual pens (1.5 $\mathrm{m}^{2}$ each). Lambs were randomly assigned to two dietary treatments, balanced for bodyweight, and adapted to the experimental diet over 8 days, during which the pre-experimental concentrate was gradually replaced with the experimental diets. After this adaptation period, lambs were fed ad libitum for 36 days with a barley-corn based concentrate diet (CON, 8 lambs) or a concentrate diet containing $200 \mathrm{~g} / \mathrm{kg}$ dry matter (DM) of whole pomegranate by-product to partially replace barley and corn (WPB, 9 lambs). Ingredients and chemical composition of the experimental diets are reported in Table 1. All the ingredients were ground (5-mm screen), mixed and pelleted (at $40{ }^{\circ} \mathrm{C}$ ) using a pelleting machine (CMS-IEM - Colognola ai Colli, Verona, Italy) to avoid selection. Lambs had free access to fresh water throughout the experiment. Every day, the amount of offered and refused diet was recorded in order to calculate the dry matter intake (DMI). Lambs were weighed every week from the beginning to the end of the trial to calculate average daily gain (ADG). 


\subsection{Slaughter procedure and samplings}

112 At the end of the trial, all animals were slaughtered on the same day at a commercial abattoir 113 according to the European Union welfare guidelines (Council Regulation no. 1099/2009). 114 Lambs were firstly stunned by a captive bolt and exsanguinated. Each carcass was immediately weighted and stored at $4^{\circ} \mathrm{C}$ for $24 \mathrm{~h}$. Then, carcasses were halved and the entire longissimus thoracis et lumborum muscle (LTL) was excised from both sides. The right LTL was immediately vacuum-packed and stored at $-80{ }^{\circ} \mathrm{C}$ until analysis of intramuscular fatty acid composition, antioxidant vitamins and antioxidant capacity. The left LTL was firstly used to measure the muscle $\mathrm{pH}$ by a $\mathrm{pH}-$ meter (HI-110; Hanna Instruments, Padova, Italy), then was aged vacuum-packaged for 3 days at $4{ }^{\circ} \mathrm{C}$, after which it was used for oxidative stability measurements.

\subsection{Feedstuffs analyses}

Samples of the experimental diets were collected at the beginning, middle, and end of the trial, vacuum-packed and stored at $-30{ }^{\circ} \mathrm{C}$. Feed sample for analysis was obtained by mixing equal amounts the above subsamples collected during the trial. Neutral detergent fibre (NDF), acid detergent fibre (ADF) and acid detergent lignin (ADL) were determined according to Van Soest, Robertson, \& Lewis (1991). Furthermore, crude protein, crude fat (ether extract) and ash were analysed according to the AOAC methods (1995).

Total phenolic compounds and total tannins in the feeds were extracted and determined as described by Natalello et al. (2019). Briefly, finely ground feeds (200 mg) were extracted sequentially in a sonicating water-bath with acetone $70 \%(\mathrm{v} / \mathrm{v})$ followed by methanol $80 \%$ $(\mathrm{v} / \mathrm{v})$. The combined supernatants were evaporated and the residue was dissolved in methanol $70 \%(\mathrm{v} / \mathrm{v})$. Total phenolic compounds were quantified by reaction of the extract with the Folin- 
135 Ciocalteu reagent $(1 \mathrm{~N})$ and sodium carbonate $20 \%(\mathrm{w} / \mathrm{v})$, after which the absorbance at 725 $\mathrm{nm}$ was measured using a double-beam spectrophotometer (model UV-1601; Shimadzu

Corporation, Milan, Italy). Non-tannin phenolics were determined with the same procedure, after removal of the tannins from the extract with insoluble polyvinylpyrrolidone (PVPP). The concentration of total tannins was calculated as difference between total phenols and total nontannin phenols. Standard solutions of tannic acid (TA) were used to prepare an external calibration curve in order to quantify phenolic compounds, which were expressed as g TA equivalents/100 g dry matter. Additionally, total condensed tannins were determined by the in situ thiolysis assay according to the method described by Gea, Stringano, Brown, and MuellerHarvey (2011) with slight modifications. In short, $200 \mathrm{mg}$ of ground feedstuffs were weighed into a screw-top glass tube, and a reagent containing $2 \mathrm{~mL}$ of $\mathrm{MeOH}, 1 \mathrm{~mL}$ of $3.3 \% \mathrm{HCl}$ in $\mathrm{MeOH}$, and $100 \mu \mathrm{L}$ of benzyl mercaptan (BM) was added. The tubes were heated at $40^{\circ} \mathrm{C}$ for $2 \mathrm{~h}$ under vigorous stirring. Then, $9 \mathrm{~mL}$ of $1 \%$ formic acid in water was added, and the tubes were subsequently vortex mixed and centrifuged for $5 \mathrm{~min}$. The supernatant was transfer to 2$\mathrm{mL}$ vials and analysed within $48 \mathrm{~h}$ by liquid chromatography-mass spectrometry (LC-MS; Agilent 1100 series, Agilent Technologies, Waldbronn, Germany) with taxifolin as an external standard. The concentration of condensed tannins was expressed as $\mathrm{g} / 100 \mathrm{~g}$ dry matter.

Tocopherols from feedstuffs were extracted and analysed as described by Valenti et al. (2018). Briefly, feed samples were homogenized with an ethanolic butylated hydroxytoluene (BHT) solution $(0.06 \%, \mathrm{w} / \mathrm{v})$ and saponified with $\mathrm{KOH}(60 \%, \mathrm{w} / \mathrm{v})$ at $70{ }^{\circ} \mathrm{C}$ for $30 \mathrm{~min}$. Tocopherols were extracted three times using hexane/ethyl acetate $(9 / 1, \mathrm{v} / \mathrm{v})$, dried under $\mathrm{N}_{2}$ and dissolved with acetonitrile. A $50 \mu \mathrm{L}$ volume was injected in a HPLC system (pump model Perkin Elmer series 200), equipped with an autosampler (model AS 950-10, Tokyo, Japan) and a Synergy Hydro-RP column $(4 \mu \mathrm{m}, 4.6 \times 100 \mathrm{~mm}$; Phenomenex, Bologna, Italy). A mobile phase consisting of acetonitrile/methanol/tetrahydrofuran $/ 1 \%$ ammonium acetate $(68 / 22 / 7 / 3, \mathrm{v} / \mathrm{v} / \mathrm{v} / \mathrm{v})$ 
was used and the flow rate was set at $2 \mathrm{~mL} / \mathrm{min}$. The tocopherols were identified using a

161 fluorescence detector (model Jasco, FP-1525) set at excitation and emission wavelengths of $295 \mathrm{~nm}$ and $328 \mathrm{~nm}$, respectively and were quantified by using external calibration curves of commercial standard compounds (Sigma Aldrich, Steinheim, Germany).

164 The feed antioxidant capacity was determined using the oxygen radical absorbance capacity 165 (ORAC). The hydrophilic and lipophilic fractions were extracted from $1 \mathrm{~g}$ finely powdered

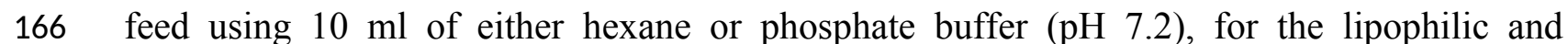
hydrophilic fractions, respectively. Both fractions were extracted by vortex-mixing the samples for $1 \mathrm{~min}$, followed by centrifugation at $4000 \mathrm{x} g$ for $30 \mathrm{~min}$ at $25^{\circ} \mathrm{C}$. The supernatant $(2 \mathrm{ml})$ was stored at $-80{ }^{\circ} \mathrm{C}$ prior to analysis. The ORAC assays were carried out on a FLUOstar OPTIMA microplate fluorescence reader (BMG LABTECH, Offenburg, Germany) following the procedure previously described by Valenti, Luciano, et al. (2019). In short, 2,20-azobis (2methylpropionamide) dihydrochloride (AAPH; Sigma-Aldrich) was used as peroxyl radical generator, Trolox was used as the reference antioxidant standard and fluorescein was used as a fluorescent probe. A $100 \mu \mathrm{L}$ volume of diluted sample, blank or Trolox calibration solution $(10-80 \mu \mathrm{mol})$ was mixed with $1 \mathrm{~mL}$ of fluorescein $(80 \mathrm{nM})$; then, $200 \mu \mathrm{L}$ of each mixture was placed in a well of the microplate. The microplate was placed in the reader and pre-incubated for 20 min at $37^{\circ} \mathrm{C}$, after which AAPH $(60 \mu \mathrm{L})$ was automatically added in each well to initiate the reaction. The fluorescence was recorded every $1.9 \mathrm{~min}$, using excitation and emission wavelengths of $485 \mathrm{~nm}$ and $520 \mathrm{~nm}$, respectively. The area under the fluorescence decay curve was measured for each sample and compared to that obtained with the Trolox standard solutions in order to express the data as $\mu$ mol Trolox equivalents (TE) / $g$ of sample. All the reaction mixtures were prepared in duplicate, and at least three independent assays were performed for each sample. 
2.5. Myoglobin concentration, fatty acids, antioxidant vitamins and antioxidant capacity of

186

187 meat

As described by Krzywicki (1982), myoglobin (Mb) was extracted by homogenization of muscle samples with phosphate buffer, followed by centrifugation at $6800 \times g$ at $4{ }^{\circ} \mathrm{C}$ and filtration through Whatman 541 paper. The filtered supernatant was scanned in a UV/VIS spectrophotometer (UV-1601; Shimadzu Co., Milan, Italy) and the absorbance at $525 \mathrm{~nm}$ was used to calculate $\mathrm{Mb}$ concentration, expressed as $\mathrm{mg} / \mathrm{g}$ of fresh tissue.

Intramuscular fatty acid composition from the same muscles used here was determined by Natalello et al. (2019). In this previous investigation, the detailed fatty acid profile was reported as $\mathrm{g} / 100 \mathrm{~g}$ of total fatty acids according to the purpose of that study. In the present study, the main classes of fatty acids, such as saturated, monounsaturated and polyunsaturated fatty acids (SFA, MUFA and PUFA, respectively), n-3 and n-6 PUFA are expressed as mg/g of muscle. In addition, the susceptibility of fatty acids to oxidation was estimated by the amount of the highly peroxidizable polyunsaturated fatty acids (HP-PUFA) with unsaturation degree $\geq 3$ and the peroxidability index was calculated according to Valenti, Natalello, et al. (2019).

The concentration of vitamin $\mathrm{E}$ in muscle ( $\alpha$ - and $\gamma$-tocopherols) was analysed as described by Luciano et al. (2017). Briefly, $2 \mathrm{~g}$ of sample was homogenized with aqueous BHT $(0.06 \%)$, saponified with ethanolic $\mathrm{KOH}(60 \%)$ at $70{ }^{\circ} \mathrm{C}$ for $30 \mathrm{~min}$ and extracted with hexane/ethyl acetate $(9 / 1, v / v)$. The extracted solution was dried under nitrogen and resuspended with in acetonitrile. The HPLC analysis of tocopherols was performed as described above for feeds. The muscle antioxidant status was measured on the lipophilic and hydrophilic fraction by the ORAC assay, using the conditions described above for feed samples. 
209 Oxidative stability was measured in fresh and cooked meat over aerobic storage, as described by Valenti, Natalello, et al. (2019). Briefly, six slices ( $2 \mathrm{~cm}$ thickness) of each left LTL muscle were cut from the 9 to the 13 ribs using a knife. Three slices were packed under vacuum and cooked for 30 min at $70{ }^{\circ} \mathrm{C}$ in a water bath. One of these was used immediately for measurement of lipid oxidation (day 0), whereas the other two slices were placed in polystyrene trays, over-wrapped with 3-layers of domestic cling film and stored in the dark at $4{ }^{\circ} \mathrm{C}$ for 2 and 4 days. The other three raw slices were immediately placed in polystyrene trays, covered as cooked meat and stored at $4{ }^{\circ} \mathrm{C}$ in dark for 0 (after 2 hours of blooming), 4 and 7 days. At the end of the respective storage time, each slice of raw meat was used for measuring colour stability by a Minolta CM 2022 spectrophotometer (d/8 geometry; Minolta Co. Ltd. Osaka, Japan) set to operate in the specular components excluded (SCE) mode and to measure with the illuminant $\mathrm{A}$ and $10^{\circ}$ standard observer. Two measurements were taken on the meat surface and the mean value was calculated. The colour descriptors L* (lightness), a* (redness), b* (yellowness), $C$ (saturation) and $h_{a b}$ (hue angle) were measured in the CIE $L^{*} a^{*} b^{*}$ colour space. The reflectance spectra from 400 to $700 \mathrm{~nm}$ wavelength were recorded for calculation of metmyoglobin percentage (MMb) formation as described by Krzywicki (1979). For both raw and cooked slices, lipid oxidation was determined by measuring the 2thiobarbituric acid reactive substances (TBARS) at the end of each storage time, as described by Valenti, Natalello et al. (2019). Meat samples (2.5 g) were homogenized with $12.5 \mathrm{~mL}$ of distilled water using a Heidolph Diax 900 tissue homogenizer (Heidolph ElektroGmbH \& Co. KG, Kelheim, Germany) operating at $9500 \mathrm{rpm}$. During the homogenization, samples were put in a water/ice bath. Subsequently, $12.5 \mathrm{~mL}$ of $10 \%(\mathrm{w} / \mathrm{v})$ trichloroacetic acid (TCA) was added to precipitate proteins, after which samples were filtered through Whatman No. 1 filter paper. The clear filtrate $(4 \mathrm{~mL})$ was added to $1 \mathrm{~mL}$ of $0.06 \mathrm{M}$ aqueous thiobarbituric acid into pyrexglass tubes. The tubes were incubated in a water bath at $80{ }^{\circ} \mathrm{C}$ for $90 \mathrm{~min}$ and the absorbance 
of each sample was read at $532 \mathrm{~nm}$ using a Shimadzu UV/vis spectrophotometer (UV-1601;

\section{5}

236

237

Shimadzu Corporation, Milan, Italy). The assay was calibrated with solutions of TEP (1,1,3,3,tetraethoxypropane) in distilled water ranging from 0 to $65 \mathrm{nmoles} / 4 \mathrm{~mL}$. Results were expressed as mg of malonaldehyde (MDA)/ $\mathrm{kg}$ of meat.

\subsection{Statistical Analysis}

Data on animal performances and intakes, as well as on fatty acid classes, myoglobin, tocopherols and antioxidant capacity of meat were analysed using the general linear model (GLM) to test the effect of the dietary treatment. Data on oxidative stability measured in raw and cooked meat were analysed using a mixed model to test the effect of the dietary treatment and of the time of storage, as well as of their interaction as the fixed factors, while individual lamb was considered a random effect. Differences between means were assessed using the Tukey's Honest Significant Difference test. Significance was declared at $P \leq 0.05$, while trends toward significance were considered when $0.05<P \leq 0.10$. Statistical analyses were performed using Minitab, version 16 (Minitab Inc., State College, PA, USA).

\section{Results}

\subsection{Feed composition, animal performances and intakes}

As shown in Table 1, the partial replacement of barley and corn with the whole pomegranate by-product produced slight variations in the nutrient composition parameters of the diet mostly related to the fibre fractions, with higher NDF and ADF in the WPB diet compared to CON. The whole pomegranate by-product contained almost $10 \% \mathrm{DM}$ of total phenolic compounds, mostly represented by tannins (98.21\% of total phenols). Consequently, the WPB diet had a greater content of total phenolic compounds and total tannins compared to the CON diet. Regarding vitamin E, $\alpha$-tocopherol represented the main compound when compared with $\gamma$ - 
259 tocopherol in the pomegranate by-product. Both compounds were found at a greater 260 concentration in the WPB diet when compared with CON. The hydrophilic fraction accounted

261 for most of the antioxidant capacity (ORAC) in all the experimental feeds analysed and the

262 WPB diet exhibited a greater antioxidant capacity (ORAC) of both hydrophilic and lipophilic 263 fractions compared to CON.

264 The dietary treatment did not affect $(P>0.05)$ the performance parameters of lambs, measured 265 meat $(P<0.05)$.

\subsection{Myoglobin, vitamin E, fatty acids and antioxidant capacity of meat.}

As shown in Table 3, the dietary treatment did not affect the ultimate $\mathrm{pH}$ of meat, the concentration of myoglobin and the intramuscular fat content $(P>0.05)$. Feeding the WPB diet increased the concentration of vitamin $\mathrm{E}$ in meat $(\alpha$ - and $\gamma$-tocopherols; $P<0.001)$. Regarding the fatty acid composition of the intramuscular fat, the dietary treatment did not affect the concentration of saturated and monounsaturated fatty acids (SFA and MUFA, respectively; $P>0.05$ ), while a greater concentration of polyunsaturated fatty acids (PUFA) was found in meat from the WPB-fed lambs $(P<0.05)$. Particularly, compared to CON, feeding WPB increased the concentration of highly peroxidizable (HP) PUFA with at least three double bonds and the peroxidability index of intramuscular fatty acids $(P<0.05)$. Lastly, as shown in Figure 1, the WPB diet increased the antioxidant capacity (ORAC) of the lipophilic fraction of 


\subsection{Meat oxidative stability}

285 The effect of the dietary treatment and time of storage on the oxidative stability parameters measured in raw and cooked meat are reported in Table 4. The time of storage affected some of the colour parameters measured in raw meat, with $a^{*}$ values decreasing over the 7 days of storage, while $\mathrm{b}^{*}$ and $\mathrm{h}_{\mathrm{ab}}$ values were increased $(P<0.001)$. Also, the percentages of metmyoglobin $(\mathrm{MMb} \%)$ increased over time, indicating meat browning $(P<0.001)$. The dietary treatment did not affect any of the colour parameters overall measured in meat during storage, except for $\mathrm{L}^{*}$ values which were lower in meat from the $\mathrm{CON}$ group $(P<0.01)$. Additionally, feeding the WPB diet reduced the average $\mathrm{MMb} \%$ measured in meat across the 7-day storage period $(P=0.05)$. In both raw and cooked meat, lipid oxidation (TBARS values) increased over storage duration $(P<0.001)$ and the WPB diet reduced the extent of lipid oxidation overall measured in meat over time $(P<0.05)$. A significant diet $\times$ time interaction was found for TBARS values measured in raw meat. Specifically, compared to day 0 , while the TBARS values increased already after 4 days in meat from CON-fed animals, lipid oxidation increased in WPB meat after 7 days $(P<0.05$; Figure 2$)$. Raw meat from lambs in the WPB treatment had lower TBARS values compared to the CON group after 7 days of storage $(P<0.05)$. Statistically comparable results were observed between fresh meat (day 0$)$ from control group and the WPB meat stored over 7 days $(P>0.05)$.

\section{Discussion}

The resistance of meat to oxidation depends upon the complex balance between pro-oxidant factors, such as readily oxidizable substrates and catalysts, and various antioxidant defences, including both endogenous systems and exogenous antioxidants of dietary origin (Bekhit et al., 2013). Among the pro-oxidant factors, heme iron in myoglobin has been demonstrated to promote the initiation of lipid oxidation (Baron \& Andersen, 2002), so that a greater content of 
myoglobin in muscle might increase its susceptibility to lipid peroxidation. Nevertheless, in 310 the present study, we did not observe differences in the concentration of myoglobin between meat from CON- and WPB-fed lambs. The fatty acid composition of the intramuscular fat is 312 another factor determining meat oxidative stability. Particularly, polyunsaturated fatty acids 313 (PUFA) are the primary target for lipid oxidation (Bekhit et al., 2013) and their susceptibility to oxidation increases with increasing degree of unsaturation (Johnson \& Decker, 2015). Therefore, feeding strategies aimed at increasing the PUFA concentration in muscle may present the drawback of impairing the oxidative stability of meat if not balanced by adequate antioxidant interventions (Bekhit et al., 2013). In the present study, we found that the concentration of PUFA was higher $(+38 \%)$ in meat from lambs fed WPB compared to the control. In a previous study, Natalello et al. (2019) investigated the effect of the whole pomegranate by-product on the fatty acid metabolism of lambs and reported the detailed fatty acid composition of muscle, liver and ruminal digesta from the same animals used in the present study. As reported in that study, the greater concentration of total PUFA observed in meat from the WPB-fed animals was due to the combined effect of both PUFA and bioactive substances (such as tannins, able to alter the ruminal lipid metabolism) present in the pomegranate byproduct. Consequently, compared to CON, meat from the WPB-fed lambs contained specific PUFA derived from the whole pomegranate by-product (i.e., conjugated linolenic acid isomers). Also, other PUFA, such as rumenic acid, were more abundant in meat from animals in the WPB treatment compared to the CON group (Natalello et al., 2019). In the present study, caused by the greater amount of highly unsaturated PUFA, we also observed a greater peroxidability index in meat from the WPB-fed lambs. Therefore, a possible higher susceptibility to lipid oxidation could be expected in meat from the WPB-fed animals. Nevertheless, no reduction of meat shelf-life was observed; on the contrary, the formation of the secondary lipid oxidation products (TBARS) was reduced in raw meat. Furthermore, meat 
from the WPB-fed lambs displayed a greater resistance to lipid oxidation even under more stressful oxidative conditions, such as cooking. These results demonstrate that feeding the whole pomegranate by-product improved the antioxidant capacity of meat.

In the present study, we measured the overall antioxidant capacity of meat using the ORAC (oxygen radical absorbance capacity) assay which was adopted because it first offers a high sensitivity compared to other common assays (Cao \& Prior, 1998). Moreover, while most of the other tests only measure antioxidants in the hydrophilic fraction, the ORAC assay has been successfully adopted to separately determine the antioxidant capacity of the lipophilic and hydrophilic fractions of the sample (Prior et al., 2003; Huang, Ou, Hampsch-Woodill, Flanagan, \& Deemer, 2002). In the case of dietary phenolic compounds, this approach can be useful to assess their antioxidant activities in the diet and their possible antioxidant effects in animal tissues, as most of these compounds and their metabolites have hydrophilic nature. Therefore, due to the greater concentration of phenolic compounds in the WPB diet compared to the CON, it is not surprising that the former displayed a much higher ORAC value in the hydrophilic fraction and this finding agree with previous reports on the antioxidant capacity of pomegranate fruits (Elfalleh et al., 2011; Valenti, Luciano et al., 2019).

Nevertheless, although the animals fed WPB ingested a higher quantity of polyphenols than those fed the CON diet control, the antioxidant capacity of the hydrophilic fraction of meat was not affected by the dietary treatment. Even if the bioavailability of phenolic compounds was not tested, this result might lead to suppose that pomegranate phenolic compounds did not contribute to improving meat oxidative stability with a mechanism that involved their intestinal absorption and transfer to the muscle as previously suggested. Kotsampasi et al. (2014) reported that a greater content of phenolic compounds in meat from lambs fed with a silage pomegranate by-product. However, the Folin-Ciocalteu method used by the authors is biased by several interfering substances, some of which present in muscle, with a consequent 
erroneous measure of the phenolic compounds (Georgé, Brat, Alter, \& Amiot, 2005). Also, among the heterogeneous class of phenolic compounds, tannins are considered to be poorly bioavailable in animals (Vasta \& Luciano, 2011; López-Andrés et al., 2013). In this context, it 362 is of note that phenolic compounds in the WPB used in the present study were almost 363 exclusively represented by tannins (approximately 98\%), in agreement with previous reports 364 (Seeram, Lee, Hardy, \& Heber, 2005; Mphahlele, Fawole, Mokwena, \& Opara, 2016; Natalello et al., 2020).

Differently from the hydrophilic fraction, our results demonstrate that feeding the whole pomegranate to lambs increased the antioxidant capacity in the lipophilic fraction of muscle. This result might be explained by the greater concentration of Vitamin E ( $\alpha$-and $\gamma$-tocopherols) in muscle from lambs in the WPB treatment, as tocopherols react in the ORAC assay (Huang et al., 2002). The composition of the diets can directly explain the results found on the concentration of vitamin $\mathrm{E}$ in meat. Indeed, vitamin $\mathrm{E}$ is highly bioavailable as it is largely hydrolysed in the intestine and then absorbed in combination with lipid micelles. For this reason, the concentration of vitamin $\mathrm{E}$ in muscle responds to its content in the diet, as extensively demonstrated in different animal species (Bellés et al., 2019; Sales \& Koukolová, 2011). Therefore, in the present study, the greater deposition of vitamin $\mathrm{E}$ in meat from the WPB-fed lambs could derive from their higher intake of tocopherols, especially $\alpha$-tocopherol which is the most bioavailable among the vitamin E isoforms (Bellés et al., 2019). Moreover, compared to the CON diet, the WPB diet contained a greater amount of lipids, which can further increase the intestinal absorption of vitamin E (Lodge, Hall, Jeanes, \& Proteggente, 2004). Finally, other possible effects of feeding whole pomegranate by-product on the concentration of vitamin $\mathrm{E}$ in meat cannot be excluded. For example, it has been suggested that dietary phenolic compounds could exert indirect antioxidant effects. Among these, polyphenols could protect and/or regenerate other antioxidant compounds, such as vitamin $\mathrm{E}$, in the 
gastrointestinal tract or in the animal tissues for the most bioavailable compounds (Halliwell, 385 Rafter, \& Jenner, 2005; Iglesias, Pazos, Torres, \& Medina, 2012). In agreement with this observation, recent studies demonstrated a greater concentration of tocopherols in meat and

387 milk from sheep fed diets supplemented with phenolic compounds (Lobón, Sanz, Blanco, Ripoll, \& Joy, 2017; Ortuño, Serrano, \& Bañón, 2015; Valenti, Natalello et al., 2019). Therefore, it can be supposed that the polyphenols contained in the pomegranate by-product used in the present study might have contributed to the greater deposition of vitamin $\mathrm{E}$ in meat from the WPB-fed animals and future studies would be necessary to investigate this possible effect.

Vitamin E has been extensively shown to be one of the main determinants of meat oxidative stability (Bellés et al., 2019). Indeed, it has been demonstrated that pro-oxidant factors, such as intramuscular polyunsaturated fatty acids and hem iron content, play a less important role when feeding strategies promote an adequate deposition of vitamin E in meat (Ponnampalam, Norn, Burnett, Dunshea, Jacobs, \& Hopkins, 2014). Therefore, in the present study, it is plausible that vitamin E exerted a considerable role in reducing the extent of lipid oxidation in raw and cooked meat from lambs fed the WPB diet. This is the first study demonstrating that vitamin E could contribute to the antioxidant capacity of dietary pomegranate by-products as, to our knowledge, no previous studies have determined the vitamin E concentration, or the lipophilic antioxidant capacity, in muscle from animals fed with pomegranate by-products. Therefore, it is not possible to fully compare our results with the existing literature and further studies would be necessary to confirm these results. Although comparisons between studies should always be made with caution due to the different experimental conditions, it is possible that vitamin E contributed to the improvement of meat oxidative stability observed also in previous studies where lambs and kids were fed with pomegranate by-products. For example, Emami, Fathi Nasri, Ganjkhanlou, Zali, et al. (2015) used a by-product mostly composed of 
pomegranate seeds and attributed the observed antioxidant effects mainly to the phenolic compounds. Nevertheless, it has been shown that tocopherols occur at higher concentrations in pomegranate seeds than in other parts of the pomegranate fruit, such as peels and pulp (Pande \& Akoh, 2009). Furthermore, tocopherols were shown to be the main contributors to the antioxidant capacity of pomegranate seed oil, while phenolic compounds are associated to the antioxidant capacity of other portions of the fruits such as peels (Elfalleh, et al. 2011). Similar considerations may apply to the results provided by other studies in which dietary pomegranate seed pulp or other by-products containing seeds reduced lipid oxidation and improved antioxidant activity in meat (Emami, Fathi Nasri, Ganjkhanlou, Rashidi, et al., 2015; 418 Kotsampasi et al., 2014).

Regarding meat colour, it is not easy to propose a plausible explanation for the higher $\mathrm{L}^{*}$ values found, in the present study, in meat from lambs given the WPB diet. Indeed, factors potentially affecting meat lightness, such as ultimate $\mathrm{pH}$, intramuscular fat and the concentration of myoglobin in meat did not differ between treatments. It is possible to suppose an effect of tannins from pomegranate in increasing $\mathrm{L}^{*}$ values, as it was reported in studies where lambs were fed with different tannin-containing feeds, such as acacia foliage, fresh sulla or carob pulp (Priolo, Waghorn, Lanza, Biondi, and Pennisi, 2000; Priolo, Ben Salem, Atti, and Nefzaoui, 2002; Priolo et al., 2005). On the other colour parameters, it is known that meat browning, caused by the redox conversion of myoglobin forms, can be evaluated by the instrumental colour measurement, with some descriptors being particularly relevant (Mancini \& Hunt, 2005). Specifically, the decrease of $a^{*}$ values and the increase of $b^{*}$ and $h_{a b}$ values over time 430 of storage observed in the present study are consistent with several shelf-life studies on lamb 431 meat stored in comparable conditions (Aouadi et al., 2014; Valenti, Natalello, et al., 2019; 432 Luciano et al., 2019). Although the saturation index (C values) has often been reported to 433 decrease following meat browning, $\mathrm{C}$ values did not change over time in the present study. In 
agreement with our results, Emani, Fathi Nasri, Ganjkhanlou, Zali, et al. (2015) studied the

effects of feeding kids with pomegranate seed pulp on meat oxidative stability and reported that, despite the variation of $a^{*}, b^{*}$ and $h_{a b}$ values, the saturation index was not affected by the storage time. Lastly, it has been reported that strategies to reduce the extent of lipid oxidation often improve the stability of myoglobin to oxidation (Faustman, Sun, Mancini, \& Suman, 2010). Therefore, in the present study, the ability of dietary pomegranate by-product to reduce lipid oxidation might explain the reduction of metmyoglobin accumulation observed in meat from WPB-fed animals compared to the CON treatment. However, it should be stressed that

443 This could partially explain the absence of differences in the colour descriptors between treatments, as well as their negligible numerical variation over time.

\section{Conclusions}

447 The results of this study provided evidence that a high amount of conventional cereal grains in 448 the diet of lambs can be replaced by whole pomegranate by-product without negative effects 449 on animal performances. Furthermore, this dietary strategy led to a reduction of lipid oxidation 450 in fresh and cooked meat during refrigerated storage, despite the greater concentration of polyunsaturated fatty acids, while the formation of metmyoglobin was also slightly reduced.

452 These results could be linked to the higher concentration of vitamin $\mathrm{E}$ in muscle from animals 453 fed whole pomegranate by-product, which was associated to the higher antioxidant capacity 454 measured in the lipophilic fraction of muscle. Therefore, these findings suggest for the first 455 time vitamin E from dietary pomegranate by-products as a main factor contributing to improve 456 meat oxidative stability. 
459 This study was supported by the project "Ricerca di Base di Ateneo DSA3/2015", University 460 of Perugia, Department DSA3 and was conducted under the 2-year collaborative research 461 program (2016-2018) established between the Departments Di3A (University of Catania) and 462 DSA3 (University of Perugia). Authors would also like to thank Mr. Chris Humphrey 463 (University of Reading) for his help with the profiling of condensed tannins in animal feed.

\section{References}

AOAC (1995). Association of Official Analytical Chemists. Official methods of analysis (16th ed.). Washington, DC:AOAC.

Aouadi, D., Luciano, G., Vasta, V., Nasri, S., Brogna, D.M.R., Abidi, S., Priolo, A., \& Ben Salem, H. (2014). The antioxidant status and oxidative stability of muscle from lambs receiving oral administration of Artemisia herba alba and Rosmarinus officinalis essential oils. Meat Science, 97, 237-243

Baron, C.P., \& Andersen, H.J. (2002). Myoglobin-induced lipid oxidation. A review. Journal of Agricultural and Food Chemistry, 50, 3887-3897

Bekhit, A. E. D. A., Hopkins, D. L., Fahri, F. T., \& Ponnampalam, E. N. (2013). Oxidative processes in muscle systems and fresh meat: Sources, markers, and remedies. Comprehensive Reviews in Food Science and Food Safety, 12(5), 565-597.

Bellés, M., del Mar Campo, M., Roncalés, P., \& Beltrán, J. A. (2019). Supranutritional doses of vitamin E to improve lamb meat quality. Meat Science, 149, 14-23

Cao, G., \& Prior, R. L. (1998). Comparison of different analytical methods for assessing total antioxidant capacity of human serum. Clinical Chemistry, 44(6), 1309-1315.

Elfalleh, W., Tlili, N., Nasri, N., Yahia, Y., Hannachi, H., Chaira, N., Ying, M., \& Ferchichi, A. (2011). Antioxidant capacities of phenolic compounds and tocopherols from Tunisian pomegranate (Punica granatum) fruits. Journal of Food Science, 76(5), C707-C713. 
484 Emami, A., Fathi Nasri, M. H., Ganjkhanlou, M., Rashidi, L., \& Zali, A. (2015). Dietary pomegranate seed pulp increases conjugated-linoleic and-linolenic acids in muscle and adipose tissues of kid. Animal Feed Science and Technology, 209, 79-89.

Emami, A., Fathi Nasri, M. H., Ganjkhanlou, M., Zali, A., \& Rashidi, L. (2015). Effects of dietary pomegranate seed pulp on oxidative stability of kid meat. Meat Science, 104, 1419.

Emami, A., Ganjkhanlou, M., Fathi Nasri, M. H., Zali, A., \& Rashidi, L. (2015). Pomegranate seed pulp as a novel replacement of dietary cereal grains for kids. Small Ruminant Research, 123(2-3), 238-245.

Faustman, C., Sun, Q., Mancini, R., \& Suman, S. P. (2010). Myoglobin and lipid oxidation interactions: Mechanistic bases and control. Meat science, 86(1), 86-94.

Gea, A., Stringano, E., Brown, R. H., \& Mueller-Harvey, I. (2011). In situ analysis and structural elucidation of sainfoin (Onobrychis viciifolia) tannins for high-throughput germplasm screening. Journal of Agricultural and Food Chemistry, 59(2), 495-503.

Georgé, S., Brat, P., Alter, P., \& Amiot, M. J. (2005). Rapid determination of polyphenols and vitamin C in plant-derived products. Journal of Agricultural and Food Chemistry, 53(5), $1370-1373$.

Halliwell, B., Rafter, J., \& Jenner, A. (2005). Health promotion by flavonoids, tocopherols, tocotrienols, and other phenols: direct or indirect effects? Antioxidant or not? The American journal of clinical nutrition, 81(1), 268S-276S.

Huang, D., Ou, B., Hampsch-Woodill, M., Flanagan, J.A., \& Deemer, E.K. (2002). Development and validation of oxygen radical absorbance capacity assay for lipophilic antioxidants using randomly methylated beta-cyclodextrin as the solubility enhancer. Journal of Agricultural and Food Chemistry, 50,1815-1821 
508 Iglesias, J., Pazos, M., Torres, J.L., \& Medina, I. (2012). Antioxidant mechanism of grape

Lobón, S., Sanz, A., Blanco, M., Ripoll, G., \& Joy, M. (2017). The type of forage and

Krzywicki, K. (1982). The determination of haem pigments in meat. Meat Science, 7(1), 2936.

Kotsampasi, B., Christodoulou, V., Zotos, A., Liakopoulou-Kyriakides, M., Goulas, P., Petrotos, K., Natas, P., \& Bampidis, V.A. (2014). Effects of dietary pomegranate byproduct silage supplementation on performance, carcass characteristics and meat quality of growing lambs. Animal Feed Science and Technology, 197, 92-102.

Krzywicki, K. (1979). Assessment of relative content of myoglobin, oxymyoglobin and metmyoglobin at the surface of beef. Meat Science, 3(1), 1-10. 
532 Luciano, G., Natalello, A., Mattioli, S., Pauselli, M., Sebastiani, B., Niderkorn, V., Copani, G., Benhissi, H., Amanpour, A., \& Valenti, B. (2019). Feeding lambs with silage mixtures of grass, sainfoin and red clover improves meat oxidative stability under high oxidative challenge. Meat Science, 156, 59-67.

Luciano, G., Roscini, V., Mattioli, S., Ruggeri, S., Gravador, R. S., Natalello, A., Lanza, M., De Angelis, A., \& Priolo, A. (2017). Vitamin E is the major contributor to the antioxidant capacity in lambs fed whole dried citrus pulp. Animal, 11(3), 411-417.

Mancini, R. A., \& Hunt, M. (2005). Current research in meat color. Meat Science, 71(1), 100121.

Mphahlele, R. R., Fawole, O. A., Mokwena, L. M., \& Opara, U. L. (2016). Effect of extraction method on chemical, volatile composition and antioxidant properties of pomegranate juice. South African Journal of Botany, 103, 135-144.

Natalello, A., Luciano, G., Morbidini, L., Valenti, B., Pauselli, M., Frutos, P., Biondi, L., Rufino-Moya, P. J., Lanza, M., \& Priolo, A. (2019). Effect of feeding pomegranate byproduct on fatty acid composition of ruminal digesta, liver and muscle in lambs. Journal of Agricultural and Food Chemistry, 67, 4472-4482.

Natalello, A., Hervás, G., Toral, P.G., Luciano, G., Valenti, B., Mendoza, A.G., Pauselli, M., Priolo, A., \& Frutos, P. (2020). Bioactive compounds from pomegranate by-products increase the in vitro ruminal accumulation of potentially health promoting fatty acids. Animal Feed Science and Technology, 259, 114355

Orak, H. H., Yagar, H., \& Isbilir, S. S. (2012). Comparison of antioxidant activities of juice, peel, and seed of pomegranate (Punica granatum L.) and inter-relationships with total phenolic, tannin, anthocyanin, and flavonoid contents. Food Science and Biotechnology, 21(2), 373-387. 
556 Ortuño, J., Serrano, R., \& Bañón, S. (2015). Antioxidant and antimicrobial effects of dietary supplementation with rosemary diterpenes (carnosic acid and carnosol) vs. vitamin E on lamb meat packed under protective atmosphere. Meat Science, 110, 62-69

Pande, G., \& Akoh, C. C. (2009). Antioxidant capacity and lipid characterization of six Georgia-grown pomegranate cultivars. Journal of agricultural and food chemistry, 57(20),

Ponnampalam, E.N., Norn, S., Burnett, V.F., Dunshea, F.R., Jacobs, J.L., \& Hopkins, D.L. (2014). The synergism of biochemical components controlling lipid oxidation in lamb muscle. Lipids, 49, 757-766

Priolo, A., Bella, M., Lanza, M., Galofaro, V., Biondi, L., Barbagallo, D., Ben Salem, H., \& Pennisi, P. (2005). Carcass and meat quality of lambs fed fresh sulla (Hedysarum coronarium L.) with or without polyethylene glycol or concentrate. Small Ruminant Research, 59, 281-288

Priolo, A., Ben Salem, H., Atti, N., \& Nefzaoui, A. (2002). Polyethylene glycol in concentrate or feedblocks to deactivate condensed tannins in Acacia cyanophylla Lindl. Foliage 2. Effects on meat quality of Barbarine lambs. Animal Science, 75, 137-140.

Priolo, A., Waghorn, G. C., Lanza, M., Biondi, L., \& Pennisi, P. (2000). Polyethylene glycol as a means for reducing the impact of condensed tannins in carob pulp: Effects on lamb growth performance and meat quality. Journal of Animal Science, 78, 810-816.

Prior, R. L., Hoang, H., Gu, L., Wu, X., Bacchiocca, M., Howard, L., Hampsch-Woodill, M., Huang, D., Ou, B., \& Jacob, R. (2003). Assays for hydrophilic and lipophilic antioxidant capacity (oxygen radical absorbance capacity $\left(\mathrm{ORAC} \mathrm{C}_{\mathrm{FL}}\right)$ ) of plasma and other biological and food samples. Journal of Agricultural and Food Chemistry, 51(11), 3273-3279. 
Salami, S. A., Luciano, G., O'Grady, M. N., Biondi, L., Newbold, C. J., Kerry, J. P., \& Priolo, A. (2019). Sustainability of feeding plant by-products: a review of the implications for ruminant meat production. Animal Feed Science and Technology, 251, 37-55

Sales, J., \& Koukolová, V. (2011). Dietary vitamin E and lipid and color stability of beef and pork: Modeling of relationships. Journal of Animal Science, 89, 2836-2848

Seeram, N., Lee, R., Hardy, M., \& Heber, D. (2005). Rapid large scale purification of 585 ellagitannins from pomegranate husk, a by-product of the commercial juice industry. Separation and Purification Technology, 41(1), 49-55.

Shabtay, A., Eitam, H., Tadmor, Y., Orlov, A., Meir, A., Weinberg, P., Weinberg Z. G., Chen, Y., Brosh, A., Izhaki, I., \& Kerem, Z. (2008). Nutritive and antioxidative potential of fresh and stored pomegranate industrial byproduct as a novel beef cattle feed. Journal of Agricultural and Food Chemistry, 56(21), 10063-10070.

Valenti, B., Luciano, G., Morbidini, L., Rossetti, U., Codini, M., Avondo, M., Priolo, A., Bella, 592 M., Natalello, A., \& Pauselli, M. (2019). Dietary pomegranate pulp: effect on ewe milk 593 quality during late lactation. Animals, 9(5), 283.

594 Valenti, B., Luciano, G., Pauselli, M., Mattioli, S., Biondi, L., Priolo, A., Natalello, A., 595 Morbidini, L., \& Lanza, M. (2018). Dried tomato pomace supplementation to reduce lamb concentrate intake: Effects on growth performance and meat quality. Meat Science, 145, $63-70$.

Valenti, B., Natalello, A., Vasta, V., Campidonico, L., Roscini, V., Mattioli, S., Pauselli, M., Priolo, A., Lanza, M., \& Luciano, G. (2019). Effect of different dietary tannin extracts on lamb growth performances and meat oxidative stability: comparison between mimosa, 
602 Van Soest, P. J., Robertson, J. B., \& Lewis, B. A. (1991). Methods for dietary fiber, neutral 603 detergent fiber, and nonstarch polysaccharides in relation to animal nutrition. Journal of 604 Dairy Science, 74(10), 3583-3597.

605 Vasta, V., \& Luciano, G. (2011). The effects of dietary consumption of plants secondary 606 compounds on small ruminants' products quality. Small Ruminant Research, 101(1-3), $607 \quad 150-159$.

608 Viuda-Martos, M., Fernández-López, J., \& Pérez-Álvarez, J. A. (2010). Pomegranate and its 609 many functional components as related to human health: a review. Comprehensive $610 \quad$ Reviews in Food Science and Food Safety, 9(6), 635-654. 
Table 1.

Ingredients, chemical composition and antioxidant capacity of the experimental diets and whole pomegranate by-product.

\begin{tabular}{|c|c|c|c|}
\hline & \multirow{2}{*}{$\begin{array}{l}\text { Whole pomegranate } \\
\text { by-product }\end{array}$} & \multicolumn{2}{|c|}{ Experimental $\operatorname{diet}^{l}$} \\
\hline & & $\mathrm{CON}$ & WPB \\
\hline \multicolumn{4}{|l|}{ Ingredients, $\mathrm{g} / 100 \mathrm{~g}$ dry matter (DM) } \\
\hline Corn & & 22.6 & 11.6 \\
\hline Barley & & 22.6 & 11.6 \\
\hline Alfalfa hay & & 19.8 & 19.8 \\
\hline Wheat bran & & 20.0 & 20.0 \\
\hline Soybean meal & & 12.0 & 14.0 \\
\hline Whole pomegranate by-product & & - & 20.0 \\
\hline Molasses & & 0.9 & 0.9 \\
\hline Mineral premix ${ }^{2}$ & & 2.1 & 2.1 \\
\hline \multicolumn{4}{|l|}{ Chemical composition, g/100 g DM } \\
\hline DM, $\mathrm{g} / 100$ as fed & 90.0 & 88.7 & 89.2 \\
\hline Crude Protein & 6.52 & 17.6 & 17.8 \\
\hline $\mathrm{NDF}^{3}$ & 28.8 & 23.3 & 26.3 \\
\hline $\mathrm{ADF}^{3}$ & 20.7 & 12.9 & 15.5 \\
\hline $\mathrm{ADL}^{3}$ & 5.52 & 2.98 & 2.70 \\
\hline Ash & 3.52 & 5.87 & 4.40 \\
\hline Crude Fat & 3.99 & 2.11 & 2.51 \\
\hline \multicolumn{4}{|l|}{ Phenolic compounds, g/100g DM } \\
\hline Total phenols ${ }^{4}$ & 9.51 & 0.30 & 1.89 \\
\hline Total tannins ${ }^{4}$ & 9.34 & 0.14 & 1.70 \\
\hline Condensed tannins & 0.80 & 0.10 & 0.20 \\
\hline \multicolumn{4}{|l|}{ Tocopherols, $\mathrm{mg} / \mathrm{kg} D M$} \\
\hline$\gamma$-Tocopherol & 11.1 & 0.74 & 2.04 \\
\hline$\alpha$-Tocopherol & 48.3 & 7.82 & 16.8 \\
\hline \multicolumn{4}{|c|}{ Antioxidant capacity (ORAC), $\mu \mathrm{mol} T E / g D M^{5}$} \\
\hline Hydrophilic fraction & 684 & 103 & 342 \\
\hline Lipophilic fraction & 27.3 & 21.1 & 31.1 \\
\hline
\end{tabular}

${ }^{I}$ CON: control barley-corn based concentrate diet. WPB: diet including $20 \%$ of whole pomegranate by-product.

${ }^{2}$ Containing: $25 \%$ calcium carbonate, $25 \%$ sodium bicarbonate, $25 \%$ bicalcic phosphate and $25 \%$ sodium chloride.

${ }^{3}$ NDF: neutral detergent fibre; ADF: acid detergent fibre; ADL: acid detergent lignin (ADL).

${ }^{4}$ Expressed as tannic acid equivalents.

${ }^{5}$ ORAC: oxygen radical absorbance capacity; TE: trolox equivalents. 
Table 2.

Effect of the dietary treatment on lamb performances and intakes.

\begin{tabular}{|c|c|c|c|c|}
\hline & \multicolumn{2}{|c|}{ Dietary treatment $^{l}$} & \multirow{2}{*}{$\mathrm{SEM}^{2}$} & \multirow{2}{*}{$P$-value } \\
\hline & $\mathrm{CON}$ & WPB & & \\
\hline \multicolumn{5}{|l|}{ Performances } \\
\hline Final body weight, kg & 23.6 & 23.1 & 0.524 & 0.637 \\
\hline Carcass weight, kg & 11.1 & 10.2 & 0.330 & 0.179 \\
\hline $\mathrm{DMI}^{3}, \mathrm{~g} /$ day & 821 & 882 & 19.50 & 0.125 \\
\hline $\mathrm{ADG}^{3}, \mathrm{~g} /$ day & 234 & 235 & 7.200 & 0.921 \\
\hline $\mathrm{FCR}^{3}, \mathrm{~g} \mathrm{DMI}^{\mathrm{g}} \mathrm{ADG}$ & 3.56 & 3.79 & 0.101 & 0.278 \\
\hline \multicolumn{5}{|c|}{ Intakes of phenolic compounds g/day } \\
\hline Total phenols & 2.49 & 16.7 & 1.700 & $<0.001$ \\
\hline Total tannins & 1.16 & 15.0 & 1.660 & $<0.001$ \\
\hline Condensed tannins & 0.08 & 0.18 & 0.012 & $<0.001$ \\
\hline \multicolumn{5}{|c|}{ Intakes of tocopherols, $\mathrm{mg} /$ day } \\
\hline$\gamma$-Tocopherol & 0.61 & 1.80 & 1.444 & $<0.001$ \\
\hline$\alpha$-Tocopherol & 6.42 & 14.8 & 1.300 & $<0.001$ \\
\hline
\end{tabular}

${ }^{1} \mathrm{CON}$ : control barley-corn based concentrate diet. WPB: diet including $20 \%$ of whole pomegranate by-product.

${ }^{2}$ SEM: standard error of the mean.

${ }^{3}$ DMI: dry matter intake; ADG: average daily gain; FCR: feed conversion ratio. 
Table 3.

Effect of the dietary treatment on the muscle $\mathrm{pH}$, myoglobin, antioxidant vitamins and oxidisable fatty acids in the intramuscular fat.

\begin{tabular}{|c|c|c|c|c|}
\hline & \multicolumn{2}{|c|}{ Dietary treatment $^{1}$} & \multirow{2}{*}{$\mathrm{SEM}^{2}$} & \multirow{2}{*}{$P$-value } \\
\hline & $\mathrm{CON}$ & WPB & & \\
\hline $\mathrm{pH}$ & 5.72 & 5.78 & 0.036 & 0.427 \\
\hline Myoglobin, mg/g of muscle & 2.68 & 2.46 & 0.093 & 0.259 \\
\hline Intramuscular fat, $\mathrm{g} / 100 \mathrm{~g}$ muscle & 1.88 & 2.01 & 0.156 & 0.690 \\
\hline \multicolumn{5}{|l|}{ Tocopherols, $n g / g$ of muscle } \\
\hline$\gamma$-Tocopherol & 13.0 & 32.0 & 2.610 & $<0.001$ \\
\hline$\alpha$-Tocopherol & 162 & 309 & 22.00 & $<0.001$ \\
\hline \multicolumn{5}{|c|}{ Fatty acids classes and oxidizable fatty acids, $\mathrm{mg} / \mathrm{g}$ of muscle } \\
\hline Saturated & 6.39 & 6.27 & 0.637 & 0.928 \\
\hline Monounsaturated & 6.62 & 6.15 & 0.566 & 0.702 \\
\hline Polyunsaturated (PUFA) & 1.30 & 1.80 & 0.121 & 0.041 \\
\hline PUFA $n-3$ & 0.13 & 0.16 & 0.011 & 0.091 \\
\hline PUFA $n-6$ & 1.08 & 1.34 & 0.086 & 0.137 \\
\hline HP-PUFA ${ }^{3}$ & 0.39 & 0.57 & 0.041 & 0.024 \\
\hline Peroxidability index ${ }^{4}$ & 2.07 & 2.85 & 0.191 & 0.042 \\
\hline
\end{tabular}

${ }^{1} \mathrm{CON}$ : control barley-corn based concentrate diet. WPB: diet including $20 \%$ of whole pomegranate by-product.

${ }^{2}$ SEM: standard error of the mean.

${ }^{3}$ Highly peroxidizable-PUFA, calculated as the sum of PUFA with three or more unsaturated bonds.

${ }^{4}$ Calculated as: peroxidability index $=\left(\sum\right.$ dienoic $\left.\times 1\right)+\left(\sum\right.$ trienoic $\left.\times 2\right)+\left(\sum\right.$ tetraenoic $\left.\times 3\right)+$ $($ pentaenoic $\times 4)+\left(\sum\right.$ hexaenoic $\left.\times 5\right)$. 
Table 4.

Effect of the dietary treatment and time of storage on the oxidative stability parameters of meat.

\begin{tabular}{|c|c|c|c|c|c|c|c|c|c|}
\hline & \multicolumn{2}{|c|}{ Dietary treatment $(\mathrm{D})^{l}$} & \multicolumn{3}{|c|}{ Time of storage $(\mathrm{T})^{2}$} & \multirow{2}{*}{$\mathrm{SEM}^{3}$} & \multicolumn{3}{|c|}{$P$-values ${ }^{4}$} \\
\hline & $\mathrm{CON}$ & WPB & 0 & 1 & 2 & & $\mathrm{D}$ & $\mathrm{T}$ & $\mathrm{D} \times \mathrm{T}$ \\
\hline \multicolumn{10}{|c|}{ Colour descriptors and metmyoglobin \% of raw meat } \\
\hline L* (lightness) & 46.99 & 49.02 & 48.57 & 48.65 & 47.48 & 0.296 & 0.005 & 0.068 & 0.533 \\
\hline $\mathrm{a}^{*}$ (redness) & 11.56 & 11.60 & $12.24^{\mathrm{a}}$ & $11.58^{\mathrm{ab}}$ & $10.93^{b}$ & 0.166 & 0.929 & $<0.001$ & 0.181 \\
\hline $\mathrm{b}^{*}$ (yellowness) & 11.21 & 11.39 & $10.15^{\mathrm{b}}$ & $11.87^{\mathrm{a}}$ & $11.93^{\mathrm{a}}$ & 0.194 & 0.663 & $<0.001$ & 0.159 \\
\hline $\mathrm{C}$ (saturation) & 16.14 & 16.29 & 15.91 & 16.59 & 16.19 & 0.214 & 0.789 & 0.474 & 0.168 \\
\hline $\mathrm{h}_{\mathrm{ab}}$ (hue angle) & 44.08 & 44.29 & $39.55^{\mathrm{c}}$ & $45.61^{b}$ & $47.45^{\mathrm{a}}$ & 0.494 & 0.620 & $<0.001$ & 0.087 \\
\hline MetMb, $\%$ of $\mathrm{Mb}$ & 47.60 & 46.03 & $39.52^{\mathrm{c}}$ & $49.16^{\mathrm{b}}$ & $51.25^{\mathrm{a}}$ & 0.762 & 0.050 & $<0.001$ & 0.498 \\
\hline \multicolumn{10}{|c|}{ Lipid oxidation (TBARS values), $\mathrm{mg} / \mathrm{kg}$ meat } \\
\hline Raw meat & 0.95 & 0.56 & $0.25^{\mathrm{b}}$ & $0.80^{\mathrm{a}}$ & $1.08^{\mathrm{a}}$ & 0.080 & 0.024 & $<0.001$ & 0.013 \\
\hline Cooked meat & 3.74 & 3.07 & $1.69^{\mathrm{c}}$ & $3.60^{\mathrm{b}}$ & $4.70^{\mathrm{a}}$ & 0.192 & 0.006 & $<0.001$ & 0.266 \\
\hline
\end{tabular}

${ }^{1} \mathrm{CON}$ : control barley-corn based concentrate diet. WPB: diet including $20 \%$ of whole pomegranate by-product.

${ }^{2}$ Time of storage $0,1,2$ correspond to: days $0,4,7$ (raw meat); days 0, 2, 4 (cooked meat)

${ }^{3} \mathrm{SEM}$ : standard error of the mean.

${ }^{4} P$-values for the effects of the dietary treatment, time of storage and of the Diet $\times$ Time interaction

a, b, c Within row, different superscript letter indicates differences $(P<0.05)$ between times of storage tested using the Tukey's Honest Significant Difference test. 
Fig 1. Effect of the dietary treatment (CON: control barley-corn based concentrate diet. WPB: diet including $20 \%$ of whole pomegranate by-product) on raw meat antioxidant capacity of (a) hydrophilic fraction and (b) lipophilic fraction. Values presented are the estimated least squares means and standard error bars. 
Fig 2. Effect of the dietary treatment (CON: control barley-corn based concentrate diet. WPB: diet including $20 \%$ of whole pomegranate by-product) and time of storage (days 0,4 and 7) on TBARS (thiobarbituric acid reactive substances) values of raw meat over aerobic storage at $4{ }^{\circ} \mathrm{C}$. Values presented are the estimated least squares means and standard error bars.

MDA: Malondialdehyde a,b,c Indicate differences between mean values $(P<0.05)$ tested using the Tukey's Honest Significant Difference test. 

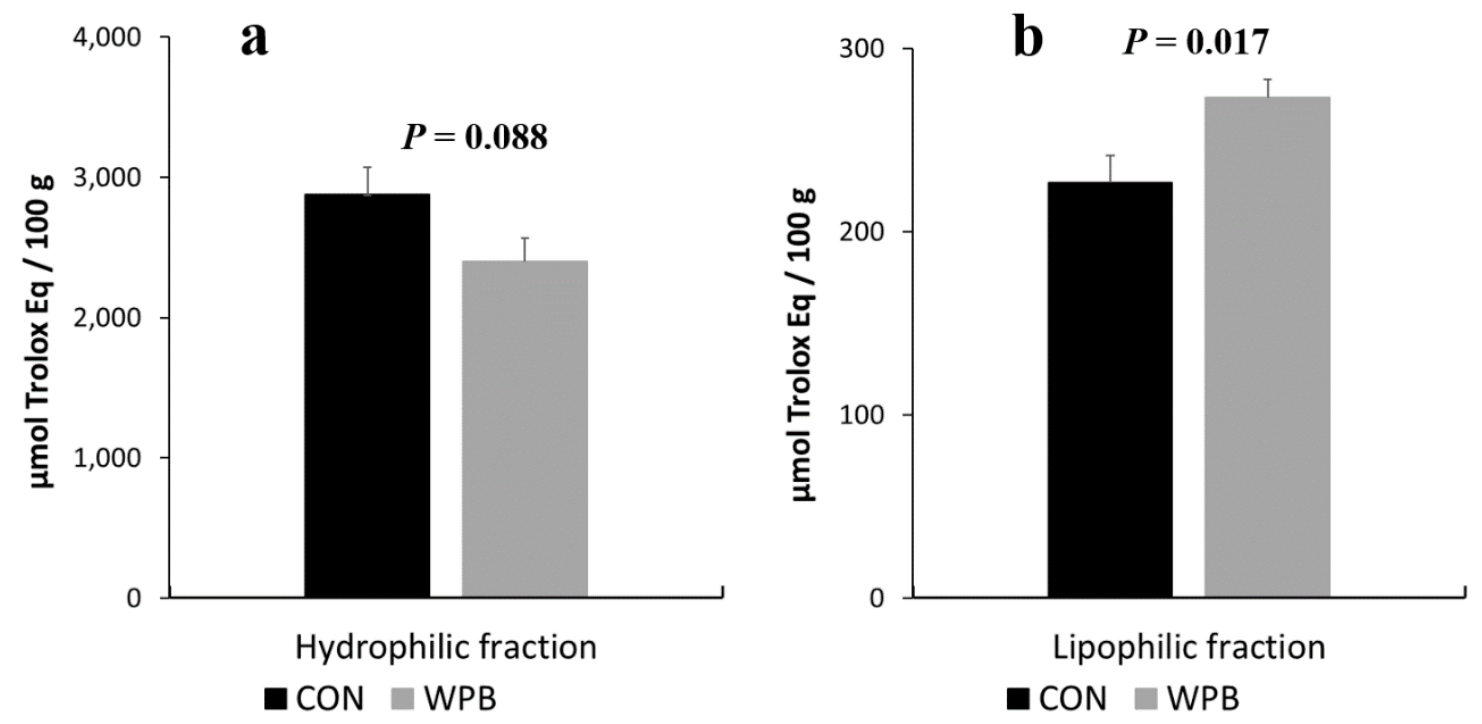


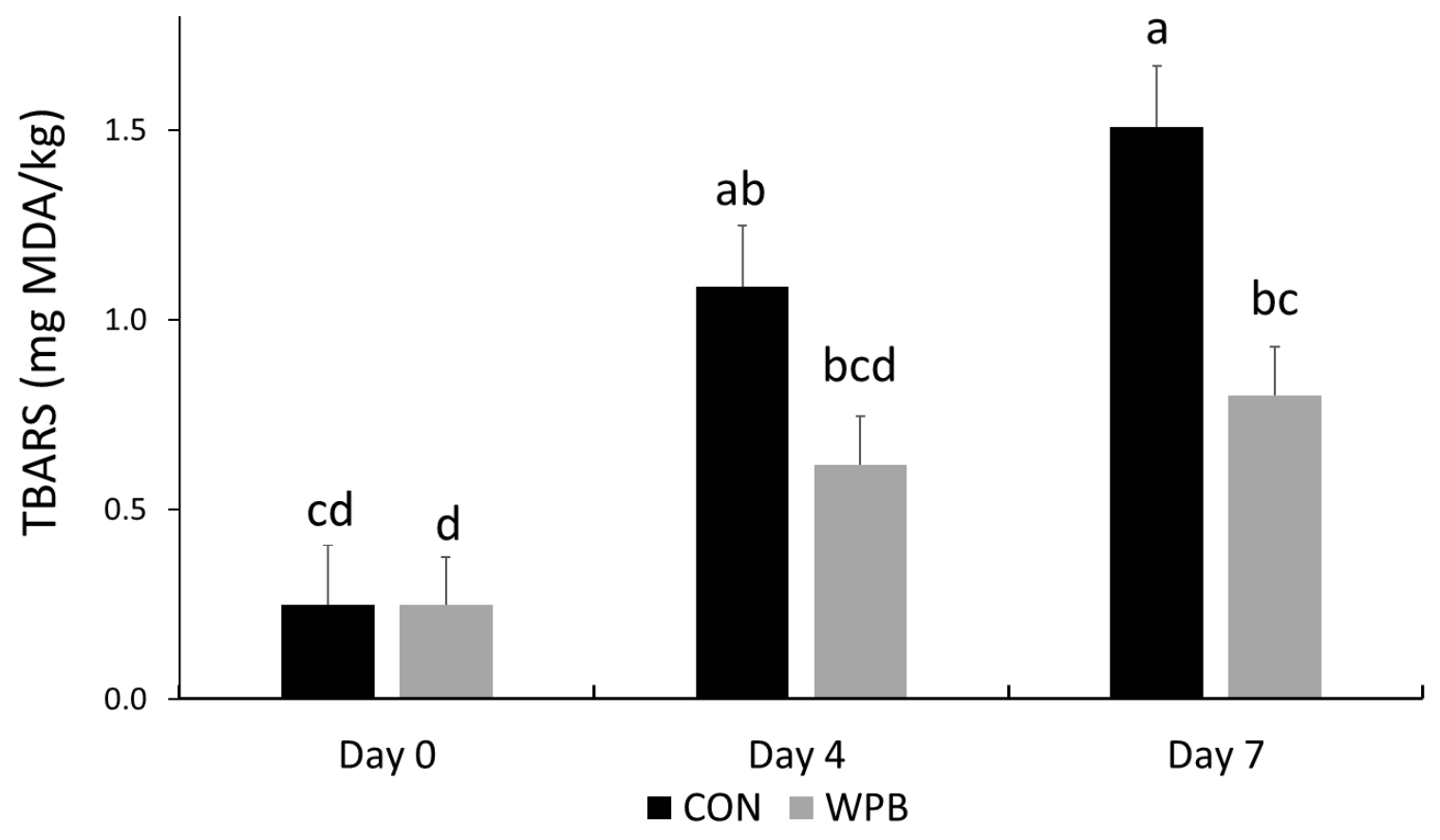

